\title{
A Balanced Scorecard for Assessing Automation in Construction
}

\author{
Isolda Agustí-Juan ${ }^{\mathrm{a} *}$, Jacqueline Glass ${ }^{\mathrm{a},}$ Vijay Pawar ${ }^{\mathrm{b}}$ \\ ${ }^{a}$ University College London, The Bartlett School of Construction and Project Management, 1-19 Torrington Place, London WC1E 7HB, UK \\ ${ }^{b}$ University College Londo, Dept. of Computer Science, Autonomous Manufacturing Lab, London WC1E 6BT, UK
}

\begin{abstract}
Despite the economic importance of the construction industry worldwide, it suffers from low productivity compared to other sectors, due to weak industrialisation, fragmented supply chain and poor collaboration. Recent national initiatives are promoting the adoption of information and automation technologies to increase efficiency, quality, safety, and reduce costs in construction. Emerging technologies will also provide highly integrated, connected and scalable new methods of construction. Nevertheless, the benefits and risks of automation in construction remain largely unknown due to the lack of standards and management tools to assess them from a holistic perspective.

The aim of this research is to develop a Balanced Scorecard (BSC) as an evaluation framework for automation in construction. A BSC is a strategic management system that links performance measurement to business strategy using a holistic set of performance assessment criteria. BSCs expand evaluation beyond financial criteria to include environmental and social considerations. The proposed BSC under development in this research uses a hierarchic system of multidimensional indicators (e.g. resource consumption, GHG emissions, costs, productivity, etc.) relevant to automation in construction, at operational, organisational and societal levels. The validity, priority and accessibility of the indicators were explored via a workshop with 20 participants from the construction industry. The workshop outcomes provided a means to focus attention on relevant key performance indicators (KPIs) for decision-making regarding construction processes. Based on the outcomes of this study, the final BSC will help construction organisations to achieve their sustainability goals and address low productivity, because automation solutions can be seen through a holistic, and pragmatic lens, thus are more likely to be included in, and contribute to, construction operations in the future.
\end{abstract}

(C) 2019 The Authors. Published by Diamond Congress Ltd.

Peer-review under responsibility of the scientific committee of the Creative Construction Conference 2019.

Keywords: balanced scorecard; automation; construction; KPIs; sustainability, assessment.

\section{Introduction}

With annual revenues of nearly $\$ 10$ trillion (6\% of global GDP), the construction industry is of strategic importance to the world's economy [1]. Despite this, productivity in the construction sector in many countries has been stagnating in recent decades and it has not been able to keep pace with the increasing productivity in other sectors [2]. The causes for this are numerous and include factors such as an adversarial culture, resistance to introduce new technologies, low industrialisation of construction processes, fragmented supply chain, poor collaboration and data interoperability [3] [4]. As a result, some countries have launched government and industry initiatives to overcome the current problems in construction. Key initiatives, such as the "Construction 2025" strategy in the UK, aim to develop an efficient and technologically advanced industry through the investment in smart construction and digital design [5]. The

*Corresponding author: Isolda Agustí-Juan, email: i.agusti@ucl.ac.uk 
digitalisation of the construction industry (referred as Construction 4.0) through the adoption of construction technologies such as Building Information Modelling (BIM) is already transforming the construction industry [6]. Over the next decade, BIM will be combined with other technologies such as the internet of things and robotic manufacturing. As a result, automated construction technologies will facilitate a highly integrated, connected and scalable construction process.

Automation in construction offers radically different ways of planning and constructing the built environment $[7,8]$, but this has implications for the environment, the economy and society. Understanding how automation can enhance productivity and efficiency in construction, while also ensuring a sustainable development, has the potential to improve performance of industrialised organisations in the round. However, evaluating automation in construction requires a well-defined and consistent framework. The aim of this research is to develop a Balanced Scorecard (BSC) to be used as an evaluation framework for automation in construction and to support the establishment of quantifiable measures and targets to improve the performance of organisations, through the balanced use of automation. This paper presents an initial set of Key Performance Indicators (KPIs) selected to evaluate automated construction processes from all sustainability dimensions. The validity and applicability of the proposed KPIs is tested and verified through a workshop with industry experts in construction and innovation. As a result, a model of BSC based on a hierarchic organisation of the indicators is proposed in this paper, which will later be verified and refined through further research phases, including the evaluation of a case study of automation in construction.

\section{Automation in Construction}

Although computer-controlled machines and robotic systems have started to be used in construction [9], the adoption of automation and robotic technologies in the building industry has remained a marginal phenomenon [8]. The notion of automation in construction is very broad, including systems from mechanical machinery manipulated by humans, including semi-automated devices with remote control, to autonomous robots with sensors and automated control features [10]. Skibniewski [11] defined construction automation as "the engineering or performance of any construction process, on-site or off-site, by means of teleoperated, numerically controlled, semiautonomous, or autonomous equipment". Mahbub [12] defined construction automation as the use of self-control mechanical and electronic machinery with intelligent control mechanisms to conduct construction tasks and operations automatically. For this study, automation in construction will refer to the use of robotic systems to perform construction tasks, including technologies and applications on both ends of automatic-autonomous spectrum.

The first attempts to introduce robot-based processes in the construction industry took place in Japan during the 1990s. The implementation of robots in construction at that time focused on the development of single-task automated devices. Such machines were designed to improve productivity by automating a conventional construction process, such as bricklaying masonry, welding, concrete slab finishing, or paint spraying [13]. More advanced examples of robotic applications in construction were not seen until 2005, when ETH Zurich started to investigate the use of industrial robots for additive prefabrication of non-standard architecture [14]. Another pioneering example of automation in construction was the project Contour Crafting (CC), a concrete-extrusion fabrication process suitable for large-scale construction [15]. Over time, the ability of robotic systems has grown, extending the scope of experimentation beyond the factory towards on-site applications. Examples of mobile robotic systems that can be applied for additive building manufacturing include semi-autonomous industrial robotic arms [16] and multi-agent autonomous flying robots [17], as shown in Fig. 1 


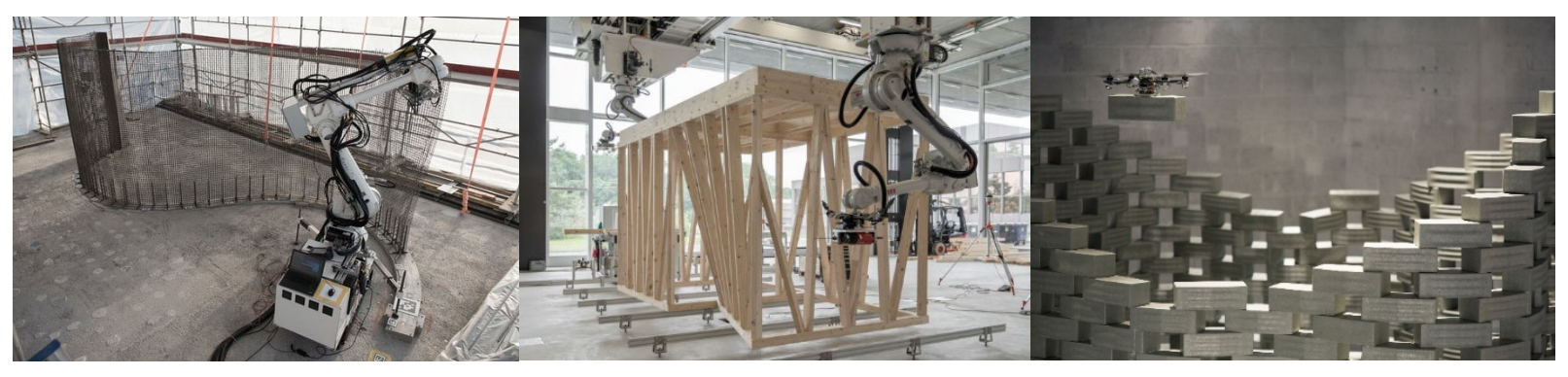

Fig. 1. Examples of automation in construction (Source: Gramazio Kohler Research, ETH Zurich [18]).

Despite the potential offered by the technology, there has been minimal research on the benefits that automation can provide to the construction sector. Initial research has explored the environmental, economic and social advantages of automation in construction, including quantification of sustainability benefits, highlighting material optimisation and functional integration [19], and the potential productivity benefits associated with the implementation of robotic systems [20]. Beyond these contributions, the performance of automated construction processes has not yet been investigated in a systematic manner and broader impacts remain largely unknown. Importantly, data uncertainty and a lack of management tools and standards in the area challenges the capacity of industrialised construction organisations to set goals, measure performance and manage changes to make their operations more sustainable.

As society becomes more aware of the activities and costs behind reported profits, companies have wider responsibilities than pursuing financial profits. Issues such as climate change, pollution, resource consumption, employment, health and safety, etc. have become highly relevant for organisations, including those in construction [21]. An increasing demand for sustainability has the potential to serve as the trigger for a large-scale deployment of automation in construction, so the construction industry needs guidance on systematic decision-making in this emergent domain. The few studies that have tried to deliver a comprehensive framework to evaluate automation in construction according to the three pillars of sustainability are far from real-world applications in an industrial context [10]. There is an urgent need for research to support the management of planning, construction and operation of building and infrastructure projects constructed with automated techniques. Understanding how these technologies can improve sustainability is essential to progress the digitalisation of the construction sector.

\section{Methodology}

\subsection{Balanced Scorecard (BSC)}

The need to report sustainability performance externally has led to a growing need to engage with sustainability issues and developments in data collection systems to integrate the social and environmental performance data into decisionmaking, risk management and performance management. Consequently, performance measurement approaches traditionally employed by organisations, such as budgeting and activity-based costing, have evolved into multidimensional performance measurement systems (PMS). PMS such as the Performance Pyramid, the Balanced Scorecard and the Performance Prism embrace a variety of financial and non-financial performance metrics to manage performance and strategic decision-making in organisations. Among PMS, Balanced Scorecards (BSCs) [22] have been applied in major building and infrastructure projects in the UK as a means to more effectively include a broader range of criteria, including sustainability, within project decision making. In this case, the BSCs expand the evaluation criteria beyond traditional indicators such as cost, time and quality to include themes related to safety, equality, environment and legacy, which support the main priorities of stakeholders. The main purpose is to ensure that environmental and social aspects are scored alongside economic, and other traditional out-turn measures, more equitably within procurement policy, embedding sustainability into business strategy.

The emergence of new digital and robotic technologies in construction requires the re-evaluation and re-engineering of business practices to successfully handle operational and organisational changes [23]. The adoption of a well-known 
and comprehensive performance management model such as the BSC for assessing automation provides a balanced and robust way of evaluating these new construction processes, but existing BSC examples do not account for automation, so a new variant is required. Such a BSC would increase the likelihood that stakeholders (e.g. construction managers) will treat innovative approaches more fairly and make use of them in decision-making on projects and organisational development.

\subsection{Key Performance Indicators (KPIs)}

A literature review and classification of existing and emerging automated construction technologies and processes guided the definition of the principal dimensions and KPIs applicable to automated construction projects. Relevant publications, such as De Schutter et al. [24], allowed the identification of relevant parameters to assess the performance of automated construction processes, such as productivity, changes in the cost structure and stakeholders, energy consumption, material production, carbon emissions, etc. Moreover, research studies focused on the development of frameworks of indicators for assessing automation in construction, e.g. Pan et al. [10], and literature related to the use of BSCs for sustainability evaluation, including Nicoletti Junior et al. [25], were reviewed. Based on this analysis, and with the goal of integrating sustainability within an automated construction process, Table 1, Table 2 and Table 3 respectively show the selected lists of indicators associated with the three dimensions of sustainability. The tables include qualitative and quantitative data required for assessing and optimising the performance of an automated construction process in relation to each indicator (e.g. costs, emissions, material use, energy demand, and employment). Each dimension presents the indicators in respect of three different levels: Operational (OP), Organisational (OR) and Societal (SO), where:

- OP indicators can be employed to evaluate performance of the construction process.

- OR indicators relate to how the automation adoption would influence performance of the organisation.

- SO indicators refer to the impact of automation on society.

Table 1. Environmental KPIs for assessing automation in construction.

\begin{tabular}{ll}
\hline Indicators & Assessment data \\
\hline Material consumption (OP) & material composition, material type (virgin, recycled), material quantity $\left(\mathrm{kg}, \mathrm{m}^{3}\right)$ \\
Waste production (OP) & waste composition, waste type (hazard, recyclable), waste quantity $\left(\mathrm{kg}, \mathrm{m}^{3}\right)$ \\
Technology production (OP) & robot type, material composition, material type (virgin, recycled) \\
Energy consumption (OP) & energy type, technology power $(\mathrm{W})$, construction time (hours) \\
GHG emissions (OP) & $\mathrm{CO}_{2}(\mathrm{~kg}), \mathrm{CH}_{4}(\mathrm{~kg}), \mathrm{N}_{2} \mathrm{O}(\mathrm{kg})$ \\
Air pollution (OP) & $\mathrm{SO}_{2}(\mathrm{~kg}), \mathrm{NO}_{\mathrm{x}}(\mathrm{kg}), \mathrm{NMVOCs}(\mathrm{kg}), \mathrm{NH}_{3}(\mathrm{~kg}), \mathrm{PM}_{10}(\mathrm{~kg}), \mathrm{PM}_{2.5}(\mathrm{~kg})$ \\
Water use (OP) & water quantity (litres) \\
Environmental strategy (OR) & contribution to environmental goals \\
Environmental compliance (OR) & compliance with environmental legislation \\
Resource scarcity (SO) & use of rare materials (high, low) \\
\hline
\end{tabular}

Table 2. Economic KPIs for assessing automation in construction.

\begin{tabular}{ll}
\hline Indicators & Assessment data \\
\hline Material cost (OP) & material cost $(\mathfrak{f})$ \\
Labour cost (OP) & number of employees, function, salary (£) \\
Technology cost (OP) & hardware cost $(\mathfrak{f})$, software cost $(\mathfrak{f})$ \\
Operational cost (OP) & energy cost $(\mathfrak{f})$, water cost $(\mathfrak{f})$, maintenance cost $(\mathfrak{f})$, license cost $(\mathfrak{f})$ \\
Waste management cost (OP) & disposal/recycling cost $(\mathfrak{E})$ \\
Productivity (OP) & construction cost $(\mathfrak{f})$, construction time (hours), project dimensions $\left(\mathrm{m}^{3}\right)$
\end{tabular}


Isolda Agustí-Juan, et al. / Proceedings of the Creative Construction Conference (2019) 023

\begin{tabular}{|c|c|}
\hline Quality (OP) & cost of rework (£), delay (hours) \\
\hline Profitability (OR) & revenue $(£)$, market share $(\%)$ \\
\hline Competitiveness (OR) & new business opportunities, dividend $(\mathfrak{f})$ \\
\hline Innovation (OR) & $\mathrm{R} \& \mathrm{D}(\mathfrak{f}), \mathrm{IP}(\mathfrak{f})$, training $(\mathfrak{f})$, technology acquisition or lease $(\mathfrak{f})$ \\
\hline Community investment (SO) & amount given as $\%$ of earnings ( $(\mathfrak{)})$ \\
\hline
\end{tabular}

Table 3. Social KPIs for assessing automation in construction.

\begin{tabular}{ll}
\hline Indicators & Assessment data \\
\hline Health \& Safety (OP) & number of incidents/hour, number of fatalities, hazards exposure \\
Working conditions (OP) & work activity (physical, intellectual), training, salary and benefits \\
Workforce diversity (OP) & employees age, gender, race, disabilities \\
Ethics in supply chain (OR) & code of conduct (anti-corruption, human rights) \\
Social compliance (OR) & compliance with social legislation (health \& safety, etc.) \\
Community benefits (SO) & employment increase (\%) \\
Social acceptability (SO) & positive media coverage \\
\hline
\end{tabular}

\subsection{KPIs validation in the industrial context}

In order to explore and verify the validity and applicability of the above indicators for assessing automation in construction in the industrial context, a workshop was organised for construction industry stakeholders. In total, 20 experts in sustainability, innovation, project management, automation, and business strategy working within UK construction organisations were recruited to participate in the workshop. They were a mixed group drawn from major contractors, consulting engineers and manufacturing organisations, with expertise in design, computing, materials, and construction and project management. The workshop was designed to collect individual views and also encourage active debate among the participants, given the emergent nature of the subject area; the approach was exploratory and essentially qualitative in nature.

Initially, the participants were divided into five working groups, each with a balanced mix of organisation types and expertise. Then, the concept and implications of automation in construction were introduced showing examples of recent applications. Once the context was clear, the environmental, economic and social indicators in Tables 1-3 were explained. The participants were then asked to freely organise the indicators according to the following criteria in the context of their organisations:

- Prioritisation (from high to low): i.e. the relevance of each indicator in respect of assessing automated construction processes.

- Ease of data access (from easy to difficult): i.e. the ease with which data on a given indicator can be accessed, currently.

Furthermore, the groups had the option to add indicators to the KPIs list. Each group presented their indicator lists on flipcharts and there was a plenary discussion to share final thoughts about the subject.

\section{Results}

\section{1. "Prioritisation" exercise}

The results of the first workshop exercise showed that the priority of the KPIs varied between groups of stakeholders and different types of organisations. Looking at the indicators from a sustainability perspective, groups 1, 3 and 4 gave higher priority to economic and social indicators, preferring the economic indicators (see Fig. 2). In contrast, group 5 indicated that environmental indicators were more relevant and group 2 distributed the priority between environmental, 
economic and social indicators more equitably. Despite this variance, all the groups considered some KPIs to be equally important. On one hand, the economic indicators Productivity and Profitability were considered highly relevant for assessing automation in construction. Similarly, the social indicator Health \& Safety was given high priority by all stakeholders, due to regulatory and legal requirements. These results showed that the main drivers of the construction industry remain financial, but the importance of social regulations is increasing in the sector. On the other hand, all stakeholders tended to award medium priority to environmental indicators such as Material consumption, Energy consumption and Waste production and low priority to Technology production. Environmental aspects are gaining relevance for construction stakeholders, but they are still considered essentially secondary when framed in an evaluation of an automated construction process.

Interestingly, looking at the KPIs from operational (OP), organisational (OR) and societal (SO) perspectives, prioritisations did not appear to be clearly related to these classification levels (see Fig. 2). However, the indicators corresponding to legal or regulatory requirements, such as Environmental Compliance and Social Compliance, were given high priority and most of them belong to the organisational level (OR).

Finally, all five groups highlighted the need for additional indicators. Among the KPIs proposed, groups 1, 2 and 5 suggested Workforce skills and training. The adoption of automation in construction will require workers to have digital skills and training of current employees will also be needed. The consideration and measurement of these issues in the BSC was clearly important for the workshop participants.

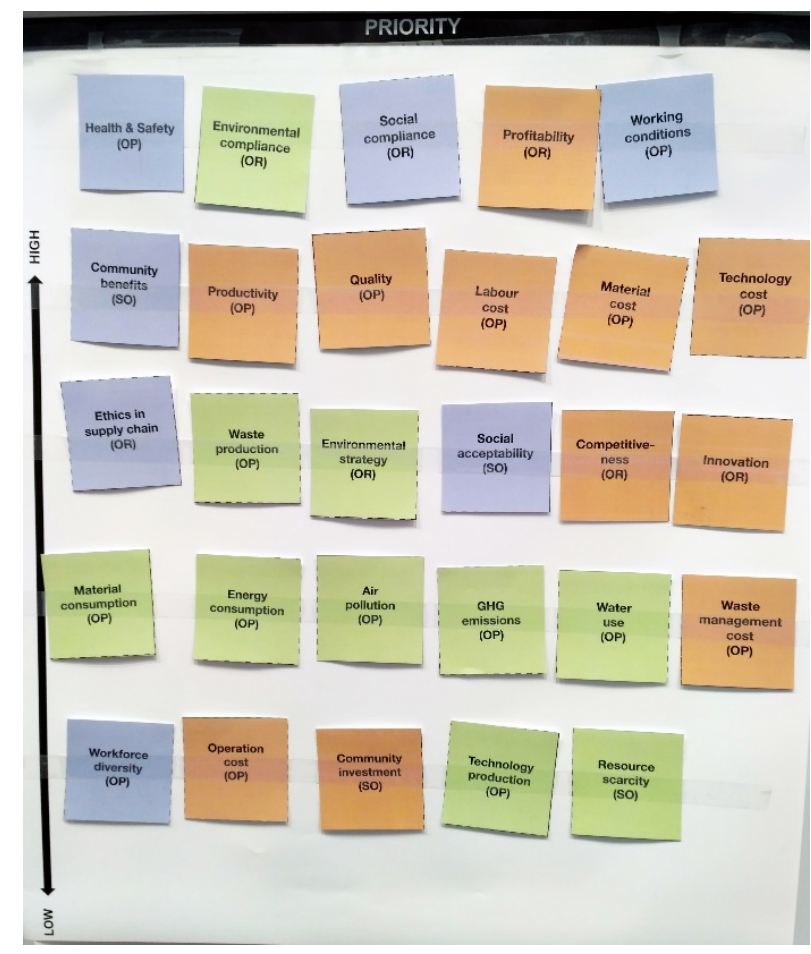

Fig. 2. Example of results from the "Prioritisation" exercise (Group 4).

\section{2. "Ease of data access" exercise}

The results of the second workshop exercise also showed that the ease of data access for assessing the KPIs varied between groups of stakeholders. Looking at the indicators from a sustainability perspective, only group 1 rated the economic indicators as having a much higher ease of data access, while the rest of the groups distributed environmental, economic and social indicators more evenly. Despite the variability between the groups, they all identified that data 
for certain KPIs was much easier to access, namely economic indicators (e.g. Material cost and Labour cost). These are well-known metrics commonly employed for assessing construction projects; all construction organisations have databases containing this type of data. In contrast, the social indicators (e.g. Ethics in the supply chain and Workforce skills and training) were considered rather more difficult to access and assess due to low data availability. Data related to parameters like working conditions, diversity, ethics are less frequently or consistently collected; they are often qualitative measures, indicating an important barrier to the inclusion and assessment of social indicators in a BSC.

Looking at the KPIs from an operational (OP), organisational (OR) and societal (SO) perspective, (unlike the prioritisation exercise) ease of data access does seem to be more closely related to these classification levels. For instance, the data required for evaluating operational indicators such as Material consumption or Operational cost were identified as easier to access than data concerning societal indicators such as Community benefits and Social acceptability. This result highlights the relevance of scale and scope when assessing the impact of automation in construction. For instance, the stakeholders clearly considered that it would be easier to measure the effects of automation on the construction process than measuring its impact on society.

\section{Proposed model for the BSC}

Based on the results of the workshop, an initial model for the Balanced Scorecard was developed, which offers an innovative method for assessing the performance of automation and robotics in the sustainability context. Fig. 3 shows the proposed model, which includes environmental indicators (green), economic indicators (orange) and social indicators (blue) distributed along two axis: priority and data access. From the list of KPIs presented in Tables 1, 2 and 3 , this model contains only those indicators that were rated consistently by the workshop participants. These indicative relationships will be used to inform the development of the final BSC.

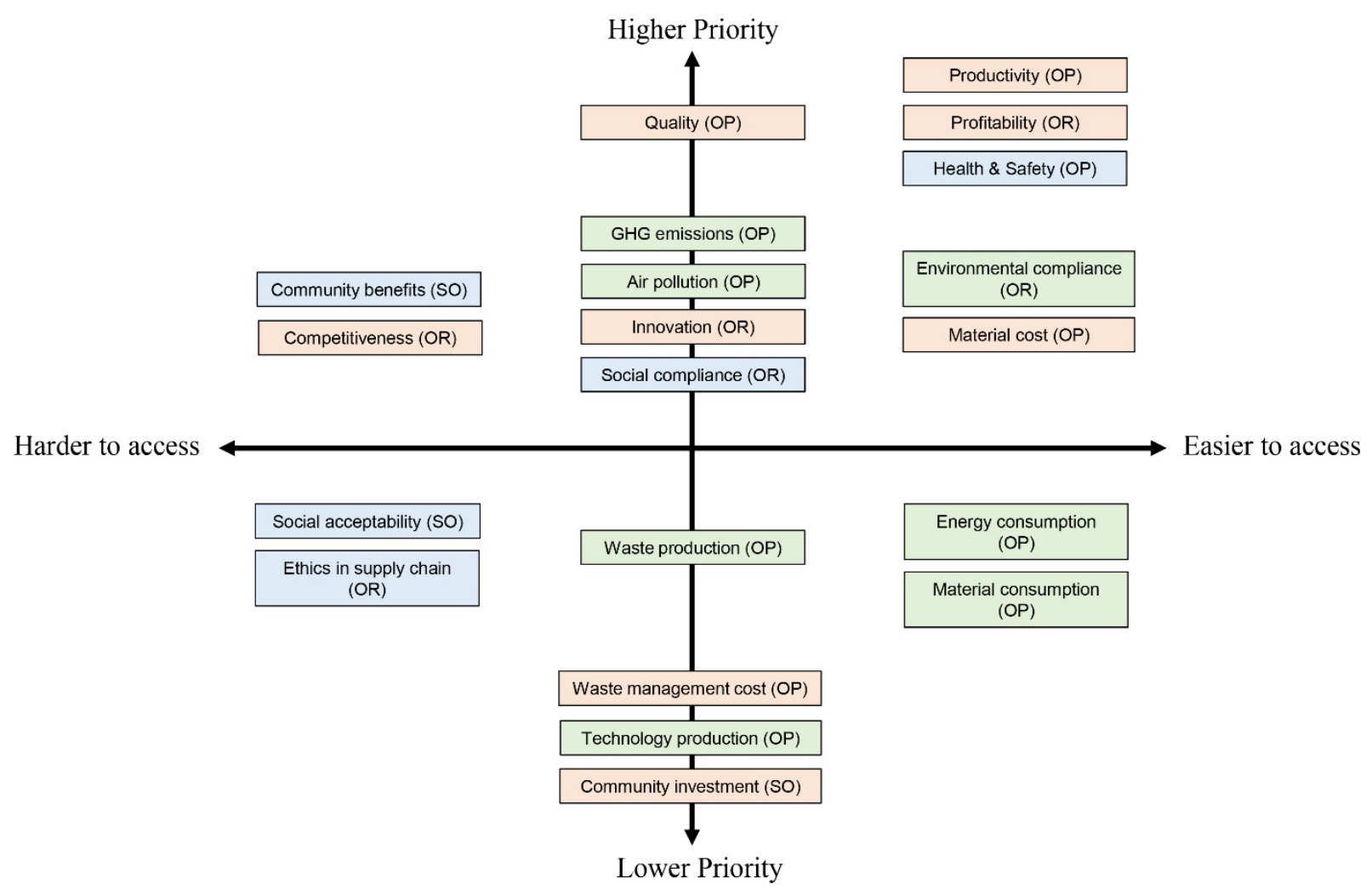

Fig. 3. Preliminary model for the Balanced Scorecard for assessing automation in construction. 
Overall, Fig. 3 shows that there is no clear prioritisation of environmental, economic or social indicators (as discrete groups), neither is there any clear prioritisation of operational (OP), organisational (OR) or societal indicators. The KPIs are distributed equitably along the priority axis, nevertheless the model shows that traditional out-turn measures tend to dominate thinking among the workshop participants. Therefore, there is a clear relation between this framework for evaluating automation in construction and traditional PMS for assessing current processes in construction. The model also shows that the priority and ease of access for indicators related to compliance of regulations is intermediate and social indicators (e.g. Ethics in the supply chain) tend to be deemed lower priority and harder to access.

Looking at the indicators in more detail, Material cost is given a higher priority than Material consumption and Waste production. This indicates that economic measures are still preferred over environmental measures to evaluate the performance of construction processes. Finally, among environmental indicators, GHG emissions is prioritised over energy consumption, although the latter is easier to access. Clearly the priority is not always influenced by data access and it may depend on how relevant is the indicator for the specific industry, in this case construction.

Based on the observations from Fig. 3, the final BSC should hierarchically organise KPIs in three generic groupings from high to low priority: Out-turn measures, Compliance measures, and Target measures (to be classified more precisely in the next stage of the research). This classification differs from previous models of BSC presented in the literature. In the original BSC model, Kaplan and Norton [22] organised measures in four perspectives: financial, customer, internal business process, and learning and growth. Later publications such as Möller and Schaltegger [26] and Nicoletti Junior et al. [25] adapted the traditional BSC management perspectives to include indicators relevant for sustainability evaluation. More recent BSC models used for the procurement of large infrastructure projects in the UK [27] have challenged the traditional BSC structure by classifying KPIs in key strategic themes that represented policy areas relevant to the objectives and requirements of the project (i.e. solution quality, costs, supply chain, employment \& skills, environmental sustainability, health \& safety and outcome benefits). In line with these project-based models, the outcome of this research will provide a BSC adapted to the needs of new automated construction processes, and which is sensitive to its industry setting. The classification of indicators in three categories will prioritise essential issues to improve the performance of organisations.

\section{Conclusion and Outlook}

Shortcomings in the construction industry have stimulated researchers and practitioners to search for new methods of increasing productivity and improving value. The adoption of greater automation offers potential, but as yet market adoption has been somewhat marginal and essentially experimental in nature. One problem is that the adoption of automation in construction requires frameworks and standards that support and guide management decisions in tune with global sustainability development trends.

The research presented in this paper is the first step to develop a robust evaluation framework for assessing automation in construction. The proposed Balanced Scorecard (BSC) model uses a hierarchic set of KPIs, which provide a holistic understanding of the impact of automated construction processes and facilitates a new pathway for achieving sustainability in buildings. The development of the BSC based on 20 industry stakeholders' views has confirmed the applicability of the framework for assessing the performance of automated and robotic construction processes in the industrial context. The workshop has also established that out-turn measures dominate thinking, followed by compliance-related issues.

Noting that the study is at an early stage of development, the research will continue and move towards a complete and reliable holistic assessment tool for real-world evaluation of automation in construction, in collaboration with construction companies. Beyond this study, the assessment of a case study of swarm-based robotic construction will be used to verify the BSC model, enhance its quality and utilise simulation data to test its effectiveness. The aim of the final BSC is to provide a realistic vision of the impact of automation and facilitate its implementation in construction to improve productivity, while ensuring the well-being of the environment and society. 
Isolda Agustí-Juan, et al. / Proceedings of the Creative Construction Conference (2019) 023

\section{Acknowledgements}

This work incorporates results from the research project "From Norm to Swarm: development of a balanced scorecard for evaluating automation in construction" funded by the Centre for Digital Built Britain (CDBB), under InnovateUK grant number RG96233. The authors would like to thank CDBB for their support, and extend their sincere gratitude to the 20 industry participants who took part in the workshop in March 2019. The research has received ethical approval from UCL.

\section{References}

[1] P. Gerbert, S. Castagnino, C. Rothballer, A. Renz, and R. Filitz, Digital in Engineering and Construction: The transformative Power of Building Information Modeling, BCG-The Boston Consulting Group, 2016.

[2] R. Agarwal, S. Chandrasekaran, and M. Sridhar, Imagining construction's digital future, McKinsey \& Company and McKinsey Global Institute, 2016.

[3] C.J. Anumba and N.F.O. Evbuomwan, Concurrent engineering in design-build projects. Constr. Manage. Econ. 15-3 (1997) 271-281. https:// doi.org/10.1080/014461997373006

[4] P. Teicholz, Labor-productivity declines in the construction industry: causes and remedies (a second look). AECbytes Viewpoint (2013).

[5] HM Government, Construction 2025. Industrial Strategy: Government and Industry in Partnership, HM Government London, 2013.

[6] R. Eadie, M. Browne, H. Odeyinka, C. McKeown, and S. McNiff, BIM implementation throughout the UK construction project lifecycle: An analysis. Autom. Constr. 36 (2013) 145-151.

[7] T. Bock and T. Linner, Robot Oriented Design, New York, Cambridge University Press, 2015.

[8] T. Bock, The future of construction automation: Technological disruption and the upcoming ubiquity of robotics. Autom. Constr. 59 (2015) 113-121. https://doi.org/10.1016/j.autcon.2015.07.022

[9] J. Willmann, M. Knauss, T. Bonwetsch, A.A. Apolinarska, F. Gramazio, and M. Kohler, Robotic timber construction — Expanding additive fabrication to new dimensions. Autom. Constr. 61 (2016) 16-23. https://doi.org/10.1016/j.autcon.2015.09.011

[10] M. Pan, T. Linner, W. Pan, H. Cheng, and T. Bock, A framework of indicators for assessing construction automation and robotics in the sustainability context. J. Cleaner Prod. 182 (2018) 82-95. https://doi.org/10.1016/j.jclepro.2018.02.053

[11] M.J. Skibniewski. Current status of construction automation and robotics in the United States of America, in: The 9th International Symposium on Automation and Robotics in Construction, Tokyo, Japan, 1992, pp. 17-26. https://doi.org/10.22260/ISARC1992/0003

[12] R. Mahbub, An investigation into the barriers to the implementation of automation and robotics technologies in the construction industry. 2008, Queensland University of Technology.

[13] M. Skibniewski and C. Hendrickson, Analysis of robotic surface finishing work on construction site. J. Constr. Eng. Manage. 114-1 (1988) 53-68. https://doi.org/10.1061/(ASCE)0733-9364(1988)114:1(53)

[14] M. Kohler, F. Gramazio, and J. Willmann, The robotic touch: how robots change architecture, Zurich, Park Books, 2014.

[15] B. Khoshnevis, D. Hwang, K.-T. Yao, and Z. Yeh, Mega-scale fabrication by contour crafting. Int. J. Ind. Syst. Eng. 1-3 (2006) 301-320.

[16] M. Giftthaler, T. Sandy, K. Dörfler, I. Brooks, M. Buckingham, G. Rey, M. Kohler, F. Gramazio, and J. Buchli, Mobile robotic fabrication at 1: 1 scale: the in situ fabricator. Constr. Rob. 1-1-4 (2017) 3-14.

[17] G. Hunt, F. Mitzalis, T. Alhinai, P.A. Hooper, and M. Kovac. 3D printing with flying robots, in: 2014 IEEE International Conference on

Robotics and Automation (ICRA), 2014, pp. 4493-4499. https://doi.org/10.1109/ICRA.2014.6907515

[18] Gramazio Kohler Research. Research. 2019 [cited 201925 03]; Available from: http://gramazio-kohler.arch.ethz.ch/web/e/forschung/index.html.

[19] I. Agustí-Juan and G. Habert, Environmental design guidelines for digital fabrication. J. Cleaner Prod. 142 (2017) $2780-2791$. https://doi.org/10.1016/j.jclepro.2016.10.190

[20] B. García de Soto, I. Agustí-Juan, J. Hunhevicz, S. Joss, K. Graser, G. Habert, and B.T. Adey, Productivity of digital fabrication in construction: Cost and time analysis of a robotically built wall. Autom. Constr. 92 (2018) 297-311. https://doi.org/10.1016/j.autcon.2018.04.004

[21] R. Gray, Social, environmental and sustainability reporting and organisational value creation? Whose value? Whose creation? Account. Auditing Account. J. 19-6 (2006) 793-819. https://doi.org/10.1108/09513570610709872

[22] R.S. Kaplan and D.P. Norton, Using the balanced scorecard as a strategic management system. Harvard business review 85-7-8 (2007) 150-+.

[23] T.D. Oesterreich and F. Teuteberg, Understanding the implications of digitisation and automation in the context of Industry 4.0: A triangulation approach and elements of a research agenda for the construction industry. Comput. Ind. 83 (2016) 121-139.

https://doi.org/10.1016/j.compind.2016.09.006

[24] G. De Schutter, K. Lesage, V. Mechtcherine, V.N. Nerella, G. Habert, and I. Agusti-Juan, Vision of 3D printing with concrete- technical, economic and environmental potentials. Cem. Concr. Res. (2018). https://doi.org/10.1016/j.cemconres.2018.06.001

[25] A. Nicoletti Junior, M.C. de Oliveira, and A.L. Helleno, Sustainability evaluation model for manufacturing systems based on the correlation between triple bottom line dimensions and balanced scorecard perspectives. J. Cleaner Prod. 190 (2018) 84-93.

http://dx.doi.org/10.1016/j.jclepro.2018.04.136

[26] A. Möller and S. Schaltegger, The sustainability balanced scorecard as a framework for eco - efficiency analysis. Journal of Industrial Ecology

9-4 (2005) 73-83. https://doi.org/10.1162/108819805775247927

[27] HM Government, Procuring Growth, Balanced Scorecard, Crown Commercial Service, 2016. 